\title{
How do Master Level Students in Computer Science Perceive Plagiarism?
}

\author{
Anders Berglund \\ Uppsala Computing Education Research Group, UpCERG, \\ Department of Information Technology, \\ Uppsala University, Uppsala, Sweden \\ Anders.Berglund@it.uu.se
}

\begin{abstract}
Plagiarism is a serious problem in computer science. This paper reports the analyses of data about plagiarism that was gathered from master level students in computing. We have identified how students perceive plagiarism, how they choose to respond when faced by a scenario involving plagiarism, and what drives them to take a particular stance or adopt an action. The data-driven analyses show complex understanding of plagiarism and a range of motives that could lead students to plagiarize. We have found discrepancies between how students understand plagiarism and how they argue they would act when facing a dilemma involving plagiarism. The implications of these perceptions and motives for computer science educators are discussed. A number of questions for discussion and further investigation are raised.
\end{abstract}

Keywords-plagiarism; computing education research; computer science education; academic integrity

\section{INTRODUCTION}

In the very beginning, all the programmers are repeating the basic sentences time and time again. After we master the programming skills, we start to write our own programs.

The above quote, from a master student in Computer Science, is part of an answer for a questionnaire on plagiarism. The student seems to suggest that novice programmers learn by copying and understanding code before they venture to write their own programs. The question then arises: Is this plagiarism? This and other questions about plagiarism that emerged from our analysis of data, which was collected as part of coursework at Uppsala University, Uppsala, Sweden, are presented in this paper.

The paper is organized as follows. We trace work related to research on plagiarism in Section II. The study setting and the methodology are described in Section III. In Section IV, we report what our students say about plagiarism, and how they said they would act if faced by a scenario to commit or abet plagiarism. We discuss the themes that arose from the analysis of the data in Section V. We state the contributions of the study and open issues for discussion amongst the computing education research community in Section VI.

\section{RELATED WORK}

The definition of what constitutes plagiarism is the subject of extensive discussion [1]. Blum [2: 27] categorizes student

\author{
Neena Thota \\ Uppsala Computing Education Research Group, UpCERG, \\ Department of Information Technology, \\ Uppsala University, Uppsala, Sweden \\ University of Saint Joseph, Macau, S.A.R. \\ Neena.Thota@it.uu.se
}

plagiarism along a continuum from lack of knowledge of citation rules; presenting incongruous pieces of copied writing; to willful, deliberate use of the works of others. Sheard and Dick [3: 47] identify the following practices of students in IT courses: (a) exam cheating, fraud, plagiarism; (b) major plagiarism (copying entire piece of work, stealing); (c) minor plagiarism (copying from a resource, resubmission); and (d) unacceptable assistance. Plagiarism, as defined by Uppsala University, is the use of someone's ideas, text, or images without acknowledging the original author. Acts of plagiarism are reported to the university disciplinary council. Students can receive consequences ranging from an official warning to suspension for 6 months for violating the plagiarism policy.

Plagiarism is an ongoing issue of concern in higher educational institutions. Plagiarism is perceived as being more of a problem for international students than native speakers. Lack of writing skills in a second language could lead to unintentional plagiarism when students are unaware of citation rules or do not have the skill to paraphrase [4]. It is difficult for Asian students, who come from a culture where repeating from a teacher's notes or textbook shows the importance of the topic, to adapt to a new learning environment that encourages original thinking and attribution of sources of information [5]. This difference between Asian cultural values and western academic practices could lead to misunderstanding of referencing conventions [6].

In recent years, the issue of plagiarism in Swedish universities has received attention. Henriksson [7] conducted a comprehensive survey at Uppsala University and found that neither teachers nor students were clear in their understanding or definition of plagiarism. Razera et al. [8] used questions modified from Henriksson's study, to investigate the awareness, attitudes, and perceptions of plagiarism by comparing students, teachers, European and non-European students at Stockholm University. Comparison of the findings between the two universities showed that teachers at Stockholm University attributed plagiarism to ambiguity in defining plagiarism and the lack of scientific writing skills among students, while teachers from Uppsala pointed to time factor and fear of failure as probable causes for students to plagiarize.

The gravity of the problem of plagiarism in computer science and information technology departments is well known. Sheard and Dick [3, 9-11] conducted two surveys of 
undergraduate students in a School of Information Technology in 2000 and in 2010. They performed a comparative analysis of the survey data [12] of computing students' practices of cheating and plagiarism. The findings revealed that students in 2010 considered cheating less acceptable and practiced it less. Sheard and Dick conjectured that the decrease in acceptability and practice could be due to measures taken by the school and the initiatives of individual academics. Their study in 2000 [3] had earlier led them to identify that students cheated when they were concerned about failure or the workload, or wanted to improve their results or catch up with missed work, or when they tried to help a friend. Reasons for not cheating were attributed to pride in one's work, a sense of moral values, and fear of penalties if caught. Studies of perceptions of plagiarism of graduate students in computing $[11,13]$ have revealed that mature students are more committed to achieving learning outcomes and therefore less susceptible than undergraduate students, who are pressured by time and fear of failure, to adopt cheating practices.

The studies reviewed here have largely focused on surveys with ratings for students to choose. Other qualitative studies have used focus group interviews with students [14] or teachers [15] to reveal insights into attitudes towards plagiarism. Our study differs in that we have elicited students' responses in their own words. We performed interpretive data analysis rather than use statistical correlations of students' perceptions and motives for plagiarizing with demographic and situational factors. In this paper, we seek to understand what students choose to do when faced by the chance to plagiarize and to use this understanding to raise further questions for investigation and for discussion amongst computing educators.

\section{StUdy SETting AND Methodology}

At Uppsala University, computing students at the masters' level are expected to work in teams and at the same time to demonstrate that they have made individual contributions. Students are encouraged to help each other but also have the requirement to present their own results. Internet resources are placed at the disposal of the students; however, all assignments are required to be products of original thinking. This creates an environment where the possibilities of committing plagiarism exist. Therefore, we elicited students' perceptions of plagiarism to find what possible motives they could have for plagiarizing.

The data, presented in this paper, was gathered from a survey in a course on academic writing for master students in Computer Science. The survey, a compulsory but anonymous part of the course, was answered by 219 students during the years 2007 to 2011 . The students were asked not to collaborate or discuss their answers.

In Section IV, we present our analysis mainly based on two topics discussed in the survey. Firstly, we asked students to write what they understood about plagiarism (presented in subsection A). Secondly, the students were asked questions about scenarios relating to plagiarism. Scenarios to elicit views of students have been used in other studies of cheating and plagiarism [13, 16]. In this paper, data collected for the following scenario is discussed in subsections B, C, and D:
You are working in the computer lab with a complicated lab that should be done individually and that should be ready the following day. You are doing well. Another student asks for your help. $\mathrm{He} / \mathrm{she}$ says: "Could you help me with this lab? If I fail, the Swedish Migration Board might say that my results are too poor, and I risk not getting a visa for the next year. I will help you next time".

1. What do you answer?

2. Please explain why you would answer in this way.

In this study, we adopted a pragmatic approach [17] and an eclectic stance to utilize a multiple data analysis approach to analyze the students' perceptions about plagiarism and the answers to the questions. The data analysis approaches are discussed next.

We analyzed and categorized the comments about plagiarism using a methodology inspired by the phenomenographic research approach [18]. Phenomenography is a qualitative, empirically based research approach that has been successfully used in research on learning of computer science in higher education. Examples of phenomenographic studies include research on students' conceptions of introductory programming [19] and of computer network protocols [20], and teachers' understanding of object-oriented programming [21].

The aim of a phenomenographic analysis is to illuminate how a phenomenon is understood within a certain cohort, in this case how the concept of plagiarism is understood within the group of master students. The experienced context of the individual, the collective, and the researcher are taken together during the analyses to understand the way the participants experienced the situation. The outcome consists of a limited set of qualitatively different categories, each of which describes certain ways of understanding the phenomena under scrutiny. In this way, the categories are abstracted from the students and do not mirror how individuals perceive something, but are instead valid for a collective view. As the categories are different descriptions of the phenomenon under investigation, they are related to each other, often in a hierarchical structure.

To analyze our second question in the survey (how students say they would act on the scenario), we used a deductive/inductive categorization method [22]. This method involves formulating a criterion of definition; examining each individual statement; coding and forming categories; revision of categories; and interpreting results. The deductive analysis presented in subsection B used predefined categories, while the inductive analyses presented in subsections $\mathrm{C}$ and $\mathrm{D}$ used emergent categories. A qualitative data analysis software package was used for this aspect of the data analysis. A verbal process of harmonization was conducted between the authors to finalize the category labels, definitions, and coding rules.

\section{FINDINGS}

In the following subsections, we present the outcomes of our analyses as categories: (A) Students' perceptions of plagiarism; (B) Students' responses to the given scenario; (C) Students' motives for refusing help in the given scenario; (D) 
Students' motives for offering to help in the given scenario. We illustrate all the categories with excerpts from the data collected.

\section{A. Perceptions of Plagiarism}

We have discerned six categories that mirror how plagiarism is understood by the students. The categories are numbered sequentially with higher ordered categories describing a more complex understanding of plagiarism.

\section{Category 1: Definition of plagiarism}

A commonly understood definition of plagiarism can be found in this category.

Plagiarism is to copy all of the material from others. Discussion, reference are not plagiarism, because I will add my opinion into discussion.

\section{Category 2: Prevents learning}

The second category expresses an understanding of plagiarism as being detrimental to the learning process.

It is a poison to your study which will make you give up the passion of solving problems by yourself.

For me it doesn't make sense. I study because I really enjoy learning stuff.

\section{Category 3: Personal issue}

The effect of plagiarism on one's own self is described in this category.

We have to take effort on whatever things we are doing. Dreaming of good results without any efforts is a wrong idea.

Plagiarism is not what I search at the university. It is not a good way to learn and I have high expectation from myself that I can create value.

Plagiarism may let you solve some problem right now, but it is really bad for you if we viewed in perspective. It may limit your creativity and make you depend on others. I will get nothing at the end.

\section{Category 4: Community issue}

This category introduces the idea of a community that is affected by the practice of plagiarism.

I think work should be borrowed, worked on and resubmitted, if we don't allow this, we are only acting like patents against information exchange. Any work in original can be taken from its authors, and *should* be worked on before submission with enhancements clearly citing the author's work and your work.

Academic dishonesty will not only have a very bad effect on the academic advancement but also is unfair to those honest and hard-working academicians and probably dampen their initiative.
Category 5: Ethical issue

In the fifth category, plagiarism is seen to have a moral basis.

Plagiarism is such a shame. It is unprofessional and unethical.

Plagiarism is a very bad behavior in my eyes. It reflects one's morals. We should be honest because we are responsible for our studies.

I think plagiarism is a kind of stealing. Be honest to others, and be honest to yourself.

\section{Category 6: Cultural issue}

The cultural context of plagiarism is introduced in this category.

I have almost zero knowledge about it. I have never heard the term plagiarism before I came to Sweden. I think cheating is known as a bad thing in most cultures. I still don't know why Swedes think that they are different and that they are very sensitive about it. I think I know what is cheating and what is not.

In my country, this is a very common problem. Most important is the weak laws. The other one is that people have not become used to obeying the rules. Another might be the bad economic and political situation.

I think the definition of plagiarism is different between different people and cultures. But however you look at it, it's not fair for other students who did the same assignment.

\section{B. Students' responses to the given scenario}

In this subsection, we have listed and illustrated what students say they would do if asked to help with an individual lab assignment:

\section{Category 1: Refusal to help}

The student will refuse to help without giving any reason.

I am sorry, I cannot.

\section{Category 2: Refusal with guidance}

The student will refuse to help, but also give advice or suggestions.

Please consult the lab coordinators for any guidance needed to complete the lab assignment. They are extremely knowledgeable and would be willing to help you.

\section{Category 3: Noncommittal}

The student will neither refuse nor offer to help.

It will depend on the help that he/she wants.

Category 4: Conditional help

The student will offer to help, but attach a condition: 
Yes, I can help you. But I only offer my opinion and my thoughts. The details the report requires should belong to you.

\section{Category 5: Unconditional help}

The student will help immediately.

Sure, I will help you. What question troubles you?

\section{Students' motives for refusing help in given scenario}

In this subsection, we identify five motives why students would refuse if asked for help with the lab assignment.

\section{Category 1: Assignment requirement}

The assignment was required by the teacher to be completed individually by a student.

This is an individual assignment. I cannot simply give him/her my solution or fix his problem by myself.

\section{Category 2: Responsibility}

It was not the responsibility of a student to help another.

I am sorry. I cannot help you to find a solution. But if you are not sure what to do, please ask the teacher.

\section{Category 3: Ethical issue}

It was unethical to help the other student.

Because if I help him/her, that means cheating. $\mathrm{He} / \mathrm{She}$ does not actually cheat the teacher, but cheat himself/herself.

Category 4: Fear of consequence

There was a possibility of penalties for the one who helped.

Because If I don't do my own assignment, Swedish Migration Board might say:"YOUR RESULTS ARE POOR", in that case I risk not getting a visa for the next year.

\section{Category 5: Helps learning}

Refusing to help was beneficial for the learning of the other student.

If he did the lab by himself, he might know about the concepts which he missed in the general lessons. And also, by doing this individually, he would think the problem by himself, which can improve the understanding about the lab, even the subject.

\section{Students' motives for offering help in given scenario}

In this subsection, we identify five motives why students would agree if asked for help with the lab assignment.

\section{Category 1: Helps learning}

Any help that was rendered was beneficial for the learning of the other student.

The point of going to college is to learn, so I think it should be fine if I help out while explaining the reasoning or preferably nudging the student in the right direction while they come up with the solution themselves.

\section{Category 2: Self learning}

It was beneficial for the student who chooses to help.

From my experience, by helping others ..., I will learn the course better.

\section{Category 3: Future help} future.

It is important to help each other, because in another day I may be in the same situation.

Category 4: Empathy

There was an understanding of what the other student was undergoing.

If I don't give my help, he/she may risk not getting a visa for the next year.

\section{Category 5: Social intent}

There was an awareness of collaboration within a community.

Because I think when I am working in a perfect synergic system like a highly ranked academic environment, I should help the system to improve by helping other elements of the system e.g. other students. The improvement of the system is my improvement.

\section{DISCUSSION}

In this section, firstly, the different understandings of the phenomenon of plagiarism are organized to relate the different categories into a structure that indicates increasingly complex understanding of plagiarism. Secondly, the ways in which students said they would act and their motives are analyzed for dilemmas and contradictions.

Table 1 summarizes the categories of descriptions of plagiarism. Each row corresponds to a category, while each column represents a single dimension of understanding of plagiarism. As can be seen (from the portions of the table that are not shaded), category 1 represents a one-dimensional view of plagiarism, whereas category 6 shows not only a more sophisticated understanding of plagiarism, but also an inclusive understanding of the other categories.

In table 1 , the first category contains only one aspect, namely the definition of plagiarism that is seen in isolation. In category 2 , the perception of plagiarism is related to its effect on the process of learning, i.e. plagiarism prevents learning. In the third category, plagiarism is seen as related to one's own ideas and as influencing one's actions. It thus becomes a personal issue. In category 4 , plagiarism is perceived as embracing the self and others and it becomes a community issue. The next category shows an understanding of plagiarism as an ethical issue that involves the self, others, and moral values. In the final category, the idea of plagiarism as involving one's self and the variation in perceptions of different groups is introduced. Thus, plagiarism is seen as a complex, cultural issue. 
TABLE I.

CATEGORIZATION OF PERCEPTIONS OF PLAGIARISM SHOWING INCREASING COMPLEXITY

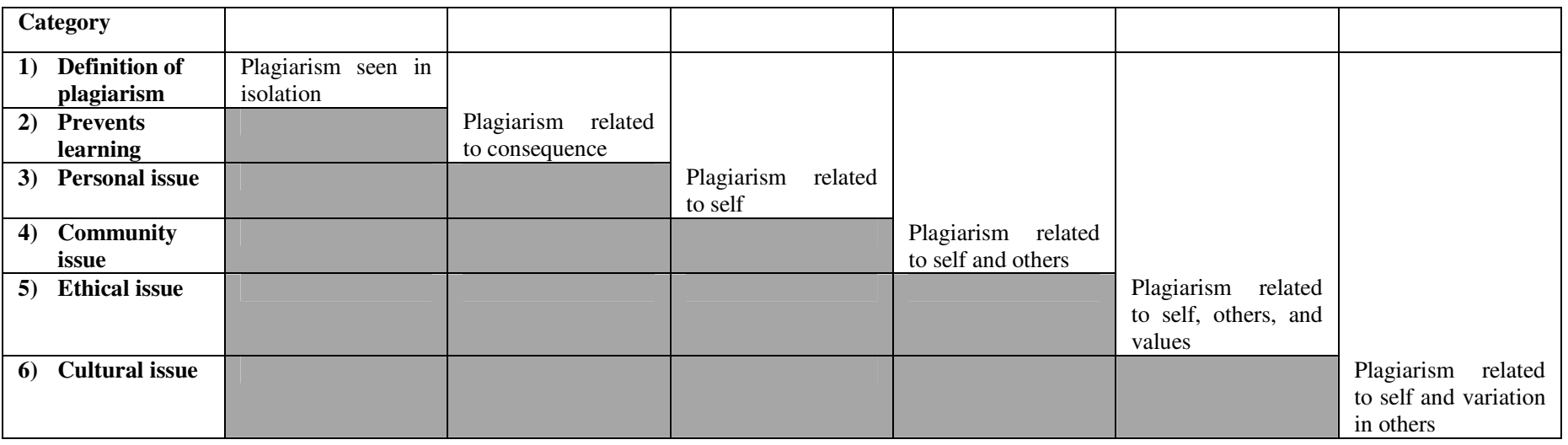

Although all our students, without exception, gave meaningful answers on what plagiarism is, the answers on how they would act if faced by the scenario showed interesting dilemmas and potential conflicts/tensions. Students' statements of how they would respond to the given scenario (presented in subsection $B$ in the previous section) ranged from categorical denial of help to offers of help. Students also stated a variety of motives (presented in subsections $\mathrm{C}$ and $\mathrm{D}$ in the previous section) for offering or refusing to help. We see the students' motives as driven by the tension between an inward-outward perspective i.e. oriented towards themselves or to others.

When oriented towards themselves, some students considered that it was not their responsibility, but that of the teacher to help students with the lab assignment. Those students who viewed being helpful in this scenario as equivalent to an act of cheating, took the ethical stance based on personal values. Fear of possible repercussion on their own grades or visa status impelled some students to say that they would not help. Other students considered helping as the improvement of their own learning, or saw it as an opportunity to expect the same kind of help in the future.

When oriented towards others, the consequences of offering help were seen as having a detrimental effect on the learning process of the student who asked for help. However, some students said that they saw this as an opportunity to contribute to the learning advancement of the other student. Some denials of help pertained to the assignment requirement that stipulated that the lab must be completed individually. These students showed compliance with the university regulations. Finally, some students decided to help, since they understood the problems associated with studying abroad.

The findings from our study also reveal that the thinking on what plagiarism means varies from culture to culture. Science (as we know it today) stems from the western culture, but is shared by different cultures. The conflicts/tensions that we have noted arise from the western values that dominate science and technology and the thinking on plagiarism that is culturally situated. We believe that all students should be made aware of the importance of the values of originality and transparency i.e.
- A students' contribution and the contribution of others should be possible to separate.

- It should be possible to trace all claims in a report back, through references, to the original author.

- The reader should have a chance to judge herself/himself what to trust and whom to trust.

- It is better to make references too clear than not clear enough.

- The text should demonstrate the students' skills and own thinking

We return now to the statement given at the beginning of this paper and to the question when to treat collaborative work in computing as plagiarism. The scenario that we gave to the students related to an individual lab assignment, and any help would be considered unacceptable. However, the beneficial effects of peer scaffolding during collaboration of novice programmers cannot be ignored [23]. Feedback from lecturers and help from internet based groups can be viewed as acceptable practices [13] in computing education. Therefore, we suggest that there is a need to inform and educate students about academic integrity and the dividing line between plagiarism and collaboration.

\section{CONCLUSIONS}

In this paper, we have presented findings from a study on master students' perceptions of plagiarism. We analyzed and categorized the different ways in which students perceived plagiarism. We also identified the ways students stated they would act and the reasons thereof when faced with a scenario for help on an individual lab assignment.

The results of this study contribute to computer science education and to research in computer science education. Firstly, they demonstrate that students hold different and increasingly complex understandings of what it means to plagiarize. The categories of descriptions can serve to inform faculty about the range of understandings that students hold about plagiarism. We see developing faculty awareness about students' perceptions of plagiarism as being essential to preventing plagiarism amongst computing education students. Secondly, the results contribute to research on plagiarism in computer science education by identifying the different ways in 
which students respond and their motives for doing so. The awareness of the underlying motives that drive students to commit plagiarism can help to formulate institutional policy and to create intervention measures to stop students from plagiarizing. Finally, the results serve as an example of a datadriven, explorative, qualitative study conducted according to theory-based analyses. Such a study can inform and enrich the discussion on plagiarism amongst master level students in computer science.

Our study opens the way for further inquiries and discussion of plagiarism. In particular, we hope to investigate the following questions:

- What are the effects of computing students' cultural background on perceptions of plagiarism?

- How do computing students see acts of plagiarism in pair programming and distributed projects?

- What are the trends from year to year in the way master level computing students perceive plagiarism, given that faculty explicitly inform students about the plagiarism policy during the orientation week?

\section{ACKNOWLEDGMENT}

We thank the students who participated in the courses.

\section{REFERENCES}

[1] D. Joyce, "Academic integrity and plagiarism: Australasian perspectives," Computer Science Education, vol. 17, pp. 187-200, 2007.

[2] S. D. Blum, My word!: Plagiarism and College Culture. Ithica, NY: Cornell University Press, 2009.

[3] J. Sheard and M. Dick, "Influences on cheating practice of graduate students in IT courses: What are the factors?," SIGCSE Bull., vol. 35, pp. 45-49, 2003.

[4] R. Barrett and J. Malcolm, "Embedding plagiarism education in the assessment process," International Journal for Educational Integrity, vol. 2, pp. 38-45, 2006.

[5] A. M. Lahur, "Plagiarism among Asian students at an Australian university offshore campus: Is it a cultural issue? A pilot study," in Proceedings of the HERDSA Conference, Miri, Sarawack, Malaysia, 2004.

[6] C. Sowden, "Plagiarism and the culture of multilingual students in higher education abroad," ELT Journal, vol. 59, pp. 226-233, July 2005.

[7] A.-S. Henriksson, "Att förebygga plagiat i studentarbeten - en pedagogisk utvecklingsmöjlighet," Rapport 7. Uppsala Universitet, Uppsala, Sweden. 2008.

[8] D. Razera, T. Cerrato, R. Ramberg, and H. Verhagen, "Plagiarism awareness, perception, and attitudes among students and teachers in
Swedish higher education-a case study," in Fourth International Plagiarism Conference, Northumbria University, Newcastle upon Tyne, UK, 2010.

[9] J. Sheard, A. Carbone, and M. Dick, "Determination of factors which impact on IT students' propensity to cheat," in Fifth Australasian Conference on Computing Education (ACE 2003), Adelaide, Australia, 2003, pp. 119-126.

[10] J. Sheard, M. Dick, S. Markham, I. Macdonald, and M. Walsh, "Cheating and plagiarism: Perceptions and practices of first year IT students," in Seventh Annual Conference on Innovation and Technology in Computer Science Education (ITiCSE '02), Aarhus, Denmark, 2002, pp. 183-187.

[11] J. Sheard, S. Markham, and M. Dick, "Investigating differences in cheating behaviours of IT undergraduate and graduate students: The maturity and motivation factors," Higher Education Research and Development, vol. 22, pp. 91-108, 2003.

[12] J. Sheard and M. Dick, "Computing student practices of cheating and plagiarism: A decade of change," in 16th Annual Joint Conference on Innovation and Technology in Computer Science Education (ITiCSE '11), Darmstadt, Germany, 2011, pp. 233-237.

[13] M. Dick, J. Sheard, and S. Markham, "Is it okay to cheat? - The views of postgraduate students," SIGCSE Bull., vol. 33, pp. 61-64, 2001.

[14] M. Devlin and K. Gray, "In their own words: a qualitative study of the reasons Australian university students plagiarize," Higher Education Research \& Development, vol. 26, pp. 181-198, 2007.

[15] R. Gururajan and D. Roberts, "Attitude towards plagiarism in information systems in Australian universities," in 9th Pacific Asia Conference on Information Systems (PACIS), Bangkok, Thailand, 2005, pp. 1568-1580.

[16] S. Marshall and M. Garry, "How well do students really understand plagiarism," in 22nd Annual Conference of the Australasian Society for Computers in Learning in Tertiary Education (ASCILITE) Brisbane, Australia, 2005, pp. 457-467.

[17] J. W. Creswell and V. L. Plano Clark, Designing and Conducting Mixed Methods Research. Thousand Oaks, CA, USA: Sage, 2007.

[18] F. Marton and S. Booth, Learning and Awareness. Mahwah, NJ, USA: Laurence Erlbaum Associates, 1997.

[19] A. Eckerdal and A. Berglund, "What does it take to learn 'programming thinking'?," in First International Computing Education Research Workshop (ICER), Seattle, WA, USA, 2005, pp. 135-142.

[20] A. Berglund, Learning computer systems in a distributed project course: The what, why, how and where. Vol. 62. Uppsala, Sweden: Acta Universitatis Upsaliensis, 2005.

[21] A. Berglund and R. Lister, "Debating the OO debate: Where is the problem?," in Seventh Baltic Sea Conference on Computing Education Research (Koli Calling), Koli National Park, Finland, 2007, pp. 171-174.

[22] P. Mayring, "Qualitative content analysis," in Forum: Qualitative Social Research. vol. 1(2), 2000.

[23] J. Carter, "Collaboration or plagiarism: What happens when students work together," SIGCSE Bull., vol. 31, pp. 52-55, 1999. 